\title{
Effect of PVP, PVA and POLE surfactants on the size of iridium nanoparticles
}

\author{
Anjali Goel*, Neetu Rani \\ Department of Chemistry, Kanya Gurukul Mahavidyalaya, Gurukul Kangri University, Hardwar, India \\ Email: "anjaligoel10@gmail.com
}

Received 16 February 2012; revised 26 March 2012; accepted 18 April 2012

\begin{abstract}
Commonly transition metal nano particle are synthesized by physical, chemical or electrochemical methods. In the present work colloidal iridium nanoparticles were synthesized by chemical oxidation method with different surfactants like poly vinyl pyrrolidone (PVP), poly vinyl alcohol (PVA) and poly oxyethylene lauryl ether (POLE). It was found that shape and size of Ir-nano particles resulted were related to kind of capping agent (surfactant) used. The characterization of the synthesized nano particle has been carried out by UV-vis, X-ray diffraction (XRD), FT-IR, scanning electron microscopy (SEM) and transmission electron microscopic (TEM) techniques. UV-vis and FT-IR confirm the oxidation of $\mathrm{IrCl}_{3}$ into $\mathrm{IrO}_{2}$ while XRD confirms the amorphous nature of the iridium nanoparticles synthesized. The morphology and size of the particle were confirmed by TEM. The average particle size determined by Scherrer equation was about $4.12 \mathrm{~nm}$ to $4.23 \mathrm{~nm}$ with PVP, 2.74 to $3.36 \mathrm{~nm}$ with PVA and 20.41 to $42.25 \mathrm{~nm}$ with POLE. Poly oxyethylene lauryl ether particles were not further analyzed because of their large size and less stability. Further particle size was confirmed with TEM, which was 4.5 $\mathrm{nm}$ with PVP and $7.0 \mathrm{~nm}$ with PVA. The particles are spherical with no agglomeration tendency.
\end{abstract}

Keywords: Nano-Materials; Surfactant; Agglomeration; PVP; PVA; POLE

\section{INTRODUCTION}

Transition metal nanoparticles are of continuing interest because of their fascinating catalytic, electronic, and optical properties. These ultrafine particles often agglomerate to form either lumps or secondary particles in order to minimize the total surface or the interfacial energy of the system Therefore, it is very important to stabilize the particles against adverse agglomeration at both the syn-

${ }^{*}$ Corresponding author. thesis and the usage stages. There have been numerous types of stabilizers that have been used as capping agent for stabilizing nanoparticles. It is well known that type of stabilizer that is used to cap the nanoparticles affects their stability and in turn affects its catalytic activity [13]. Iridium is particularly an interesting transition-metal catalyst. There have been reports of unusually high catalytic activity from molecular iridium clusters [4]. A few reports of iridium nanoparticles synthesis exist in the literature $[5,6]$. In the present work iridium nanoparticles are successfully prepared by refluxing the alcohol water solution of iridium trichloride in the presence of polymer such as poly vinyl pyrrolidone, polyvinyl alcohol and poly oxyethylene lauryl ether (abbreviated as PVP, PVA and POLE respectively). The water soluble alcohol like methanol, ethanol and propanol are used as oxidant for the synthesis of iridium nano clusters.

\section{EXPERIMENT}

\subsection{Synthesis}

In order to prepare stable metal cluster with a defined particle size below $10 \mathrm{~nm}$ and narrow size distribution, suitable solvent (oxidant) and an effective method of controlling the metal particle size has been used. In the present work iridium nanoparticles (abbreviated as Irnano) are prepared by refluxing the alcohol (methanol, ethanol and propanol) [7] water solution of iridium trichloride, and one of the protective agent such as polyvinyl pyrrolidone (PVP) [8] poly vinyl alcohol (PVA) or poly oxyethylene lauryl ether (POLE) $[9,10]$. Poly (Nvinyl-2-pyrrolidone) (PVP), poly vinyl alcohol (PVA), poly oxyethylene lauryl ether (POLE) were obtained from Merck and used as such. All the other reagents were also of analytical grade.

\subsection{Characterization}

UV-vis spectrophotometer-117 was used for spectral measurements. X-Ray-diffraction (XRD) measurements were performed on the dry powders using Bruker Axs 
D-8 Advance diffractometer with a scan rate $1^{\circ} \cdot \mathrm{min}^{-1}$ and $\mathrm{CuK}_{\alpha}(\lambda=0.154 \mathrm{~nm})$ radiation. Transmission electron microscopy (TEM) was carried out with a JEOL, JEM-1011 electron microscope.

\section{RESULTS AND DISCUSSION}

Size controlled synthesis was carried out by varying the amount of iridium precursor, $\mathrm{NaOH}$, stabilizer and alcohol as described in Tables 1, 2 \& $\mathbf{3}$ respectively. For monitoring the progress of the metal colloid formation UV-vis spectroscopy is used. As can be seen from Figure 1(c) initially reaction mixture shows an absorption peak at $206 \mathrm{~nm}$ which starts disappearing with the passage of time [11]. After about 25 minutes refluxing this absorption peak disappeared completely and a new peak appeared at around $230 \mathrm{~nm}$ indicating the formation of $\mathrm{IrO}_{2}$ nanoparticles [12]. No further change was observed. The colour of solution changes from yellow to blackbrown. The same type of spectra was obtained with PVP and PVA as shown in Figures 1(a) and 1(b) respectively.
The amorphous nature of the particles was determined by XRD. XRD was performed on the dry powders obtained after evaporation of solvent. Figures 2, 3 \& 4 show the XRD patterns of colloidal Ir-nano prepared by method a, b, c, d \& e as represented in the Tables 1, 2 \& 3 respectively. The XRD spectra of Ir-nano show mainly two broad peaks at 2-theta about $28^{\circ} \& 40^{\circ}$ at reflection planes $\mathrm{IrO}_{2}(110)$ and $\mathrm{IrO}_{2}(200)$ respectively which are characterstics of isolated $\mathrm{IrO}_{2}$ nanoparticles. The diffraction peaks also show the amorphous nature of the sample [13]. Analysis of peaks using Scherrer equation gives an estimate of particle diameter. The diameter of particles calculated by Scherrer equation are given in Tables 1-3. The particles synthesized using POEL are large in size and less stable so further analysis of these particles was not carried out.

FT-IR Spectroscopy measurements were performed with the purpose of learning about the role of the solvent and stabilizer in the formation of iridium nanoparticles. The peaks were identified by literature value $[14,15]$.

Table 1. Synthesis conditions and particle size of Ir-nano with PVP.

\begin{tabular}{|c|c|c|c|c|c|c|c|}
\hline \multirow{2}{*}{ S.No. } & \multirow{2}{*}{ Method } & \multirow{2}{*}{$(\mathrm{PVP}) / \mathrm{IrCl}_{3} \cdot \mathrm{xH}_{2} \mathrm{O}$} & \multirow{2}{*}{ Solvent } & \multirow{2}{*}{ Solvent (ml) } & \multirow{2}{*}[\mathrm{NaoH}]{$\mathrm{Ml}$} & \multicolumn{2}{|c|}{ Approx. particle size (nm) } \\
\hline & & & & & & XRD & TEM \\
\hline 1. & A & $8.69 \times 10^{-5} / 7.07 \times 10^{-4}$ & Methanol & $35 \mathrm{ml}$ & $1 \mathrm{ml}$ & $3.16,5.67$ & - \\
\hline 2. & B & $8.69 \times 10^{-5} / 7.07 \times 10^{-4}$ & Methanol & $25 \mathrm{ml}$ & $1 \mathrm{ml}$ & $4.12,4.23$ & $4.5 \mathrm{~nm}$ \\
\hline 3. & $\mathrm{C}$ & $8.69 \times 10^{-5} / 7.07 \times 10^{-4}$ & Methanol & $25 \mathrm{ml}$ & $2 \mathrm{ml}$ & $3.91,4.46$ & $4.2 \mathrm{~nm}$ \\
\hline 4. & $\mathrm{D}$ & $8.69 \times 10^{-5} / 7.07 \times 10^{-4}$ & Ethanol & $25 \mathrm{ml}$ & $1 \mathrm{ml}$ & $43.6,42.1,48.4$ & $65.16 \mathrm{~nm}$ \\
\hline 5. & E & $8.69 \times 10^{-5} / 7.07 \times 10^{-4}$ & n-propanol & $25 \mathrm{ml}$ & $1 \mathrm{ml}$ & $41.2,42.0,43.4$ & $38.6 \mathrm{~nm}$ \\
\hline
\end{tabular}

Table 2. Synthesis, conditions and particle size of Ir-nano with PVA.

\begin{tabular}{|c|c|c|c|c|c|c|c|}
\hline \multirow{2}{*}{ S.No. } & \multirow{2}{*}{ Method } & \multirow{2}{*}{$\mathrm{PVA} / \mathrm{Ircl}_{3} \cdot \mathrm{xH}_{2} \mathrm{O}$} & \multirow{2}{*}{ Solvent } & \multirow{2}{*}{ Solvent (ml) } & \multirow{2}{*}{ [NaoH] Ml } & \multicolumn{2}{|c|}{ Approx. particle size (nm) } \\
\hline & & & & & & XRD & TEM \\
\hline 1 & A & $4.34 \times 10^{-5} / 2.23 \times 10^{-4}$ & Methanol & $25 \mathrm{ml}$ & $1 \mathrm{ml}$ & $2.74,3.36$ & $7.00 \mathrm{~nm}$ \\
\hline 2. & B & $2.17 \times 10^{-5} / 1.12 \times 10^{-4}$ & Methanol & $25 \mathrm{ml}$ & $1 \mathrm{ml}$ & $2.92,4.70$ & - \\
\hline 3. & $\mathrm{C}$ & $4.34 \times 10^{-5} / 2.23 \times 10^{-4}$ & Ethanol & $25 \mathrm{ml}$ & $1 \mathrm{ml}$ & $2.65,4.46$ & - \\
\hline 4. & $\mathrm{D}$ & $2.17 \times 10^{-5} / 1.12 \times 10^{-4}$ & Ethanol & $25 \mathrm{ml}$ & $1 \mathrm{ml}$ & 6.83, 8.32, 3.38 & - \\
\hline 5. & $\mathrm{E}$ & $4.34 \times 10^{-5} / 2.23 \times 10^{-4}$ & 2-propanol & $25 \mathrm{ml}$ & $1 \mathrm{ml}$ & $8.19,7.44,7.09,11.95$ & - \\
\hline 6. & $\mathrm{~F}$ & $2.17 \times 10^{-5} / 1.12 \times 10^{-4}$ & 2-propanol & $25 \mathrm{ml}$ & $1 \mathrm{ml}$ & $3.15,4.03$ & - \\
\hline
\end{tabular}

Table 3. Synthesis conditions and particle size of Ir-nano with POLE.

\begin{tabular}{|c|c|c|c|c|c|c|c|}
\hline \multirow{2}{*}{ S.No. } & \multirow{2}{*}{ Method } & \multirow{2}{*}{ [Iridium tri chloried] } & \multirow{2}{*}{ Solvent } & \multirow{2}{*}{ Solvent (ml) } & \multirow{2}{*}[\mathrm{NaoH}]{$\mathrm{ml}$} & \multicolumn{2}{|c|}{ Approx.particle size (nm) } \\
\hline & & & & & & XRD & TEM \\
\hline 1. & a. & $4.34 \times 10^{-5} / 2.23 \times 10^{-4}$ & Methanol & $25 \mathrm{ml}$ & $1 \mathrm{ml}$ & $20.41,41.77,42.25$ & $68.19 \mathrm{~nm}$ \\
\hline 2. & b. & $4.34 \times 10^{-5} / 2.23 \times 10^{-4}$ & Methanol & $35 \mathrm{ml}$ & $1 \mathrm{ml}$ & $27.22,41.82,42.25$ & \\
\hline 3. & c. & $2.17 \times 10^{-5} / 1.12 \times 10^{-4}$ & Methanol & $25 \mathrm{ml}$ & $1 \mathrm{ml}$ & $16.38,27.29,20.9028 .45$ & - \\
\hline 4. & d. & $4.34 \times 10^{-5} / 2.23 \times 10^{-4}$ & Ethanol & $25 \mathrm{ml}$ & $1 \mathrm{ml}$ & 26.92, 27.88 & - \\
\hline 5. & e. & $4.34 \times 10^{-5} / 2.23 \times 10^{-4}$ & 2-propanol & $25 \mathrm{ml}$ & $1 \mathrm{ml}$ & $4.03,4.11$ & - \\
\hline
\end{tabular}




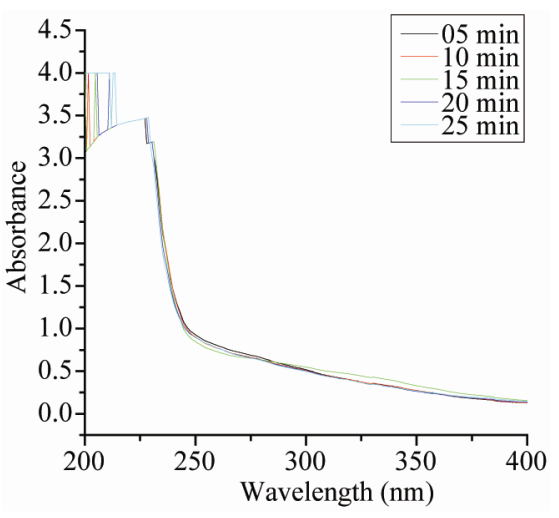

(a)

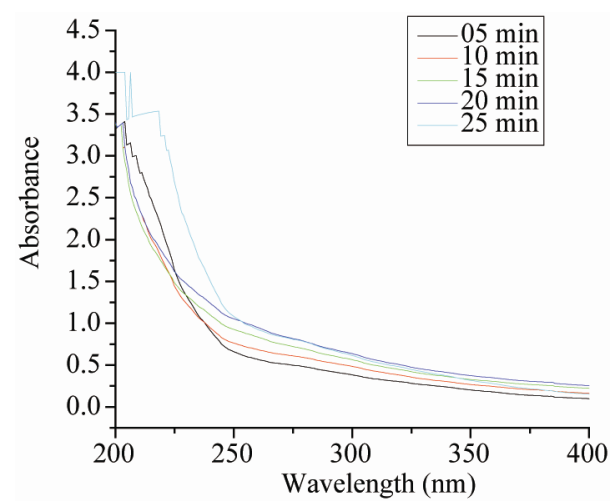

(b)

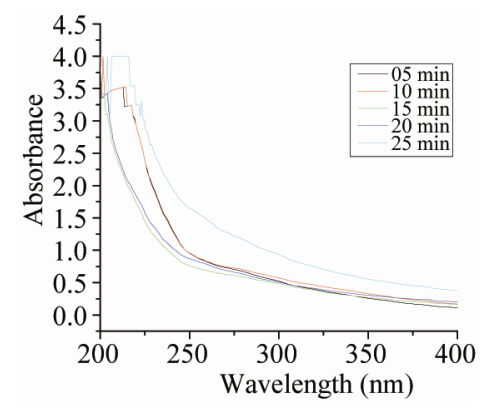

(c)

Figure 1. UV-vis spectra during the formation of Ir-nano at different time with (a) $\mathrm{PVP}-\mathrm{IrCl}_{3}$ methanol-water system; (b) PVA-IrCl 3 -methanolwater system; (c) POLE-IrCl 3 -methanol-water system.

The peaks under the region $2665 \mathrm{~cm}^{-1}$ and $2773 \mathrm{~cm}^{-1}$ may be due to Ir(III) but a new peak near the frequency $2015 \mathrm{~cm}^{-1}$ indicates the formation of iridium oxide. The red shift of resonance peak of pure stabilizer at $1700 \mathrm{~cm}^{-1}$ to $1664 \mathrm{~cm}^{-1}$ indicates the interaction of $>\mathrm{C}=\mathrm{O}$ group of stabilizer with Ir-nano. The presence of same bands at about $1500 \mathrm{~cm}^{-1}, 1461 \mathrm{~cm}^{-1}$ (aromatic C-C str, N-H bending) show that these groups do not interact with Ir-nano.

TEM is one of the most important required methods for the characterization of nano materials. It has the unique ability to prove the size and shape of the particles.

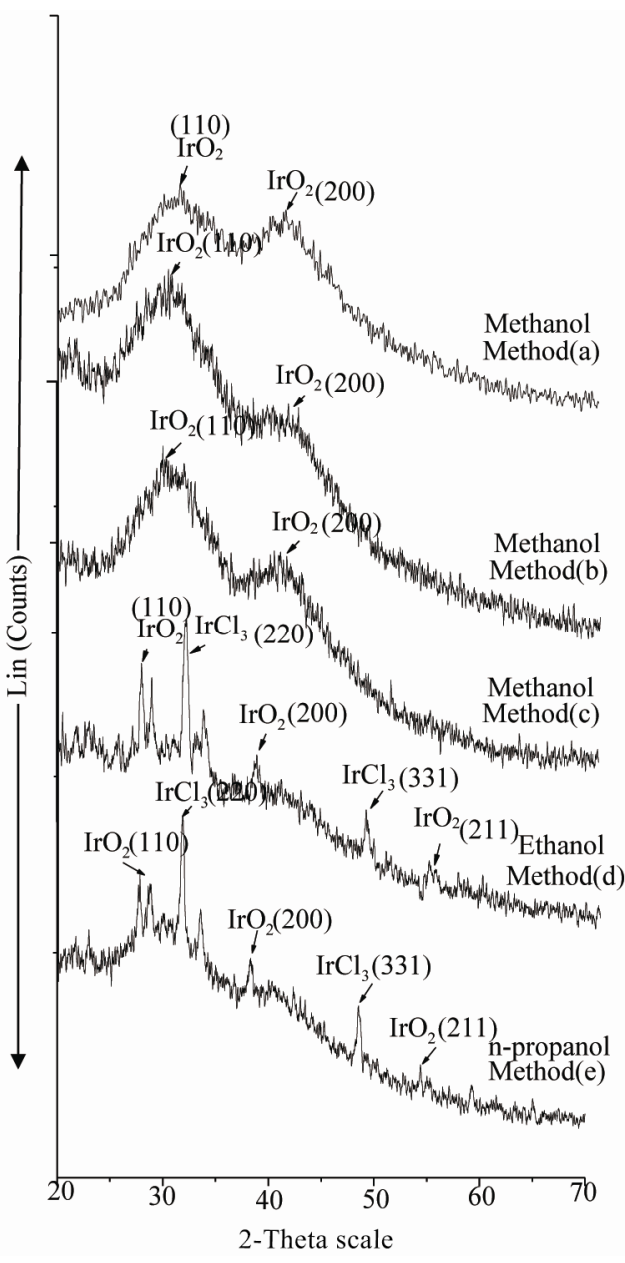

Figure 2. XRD spectra of Ir-nano prepared with methanol, ethanol and propanol using PVP as stabilizer.

Figures 5(a)-(c) show the transmission electron micrographs and the size distribution of the colloidal Ir-nano protected by PVP, PVA and POLE respectively. The average diameter of the metal nanoparticle was 4.2 to 4.5 $\mathrm{nm}$ with PVP, $7.0 \mathrm{~nm}$ with PVA and $68.16 \mathrm{~nm}$ with POLE respectively with methanol as oxidizing agent, while with ethanol and propanol particle size is larger as compared to methanol.

Thus from the above results it can be revealed that Ir-nano particles of size less than $10 \mathrm{~nm}$ can be synthesized using method "b" (Table 1), method "a" (Table 2) and method "e" (Table 3) when PVP, PVA and POLE respectively are the stabilizers.

PVP stabilized Ir-nano: A comparison of the data presented in Table $\mathbf{1}$ show that as the boiling point of oxidant increases size of particle increases. The diameter ranges between $3.16 \mathrm{~nm}$ to $48.4 \mathrm{~nm}$. It is also clear from the data that increase in $\mathrm{NaOH}$ concentration (method-c) does not show any remarkable effect on particle size but the decrease in oxidant concentration (method-b) in- 


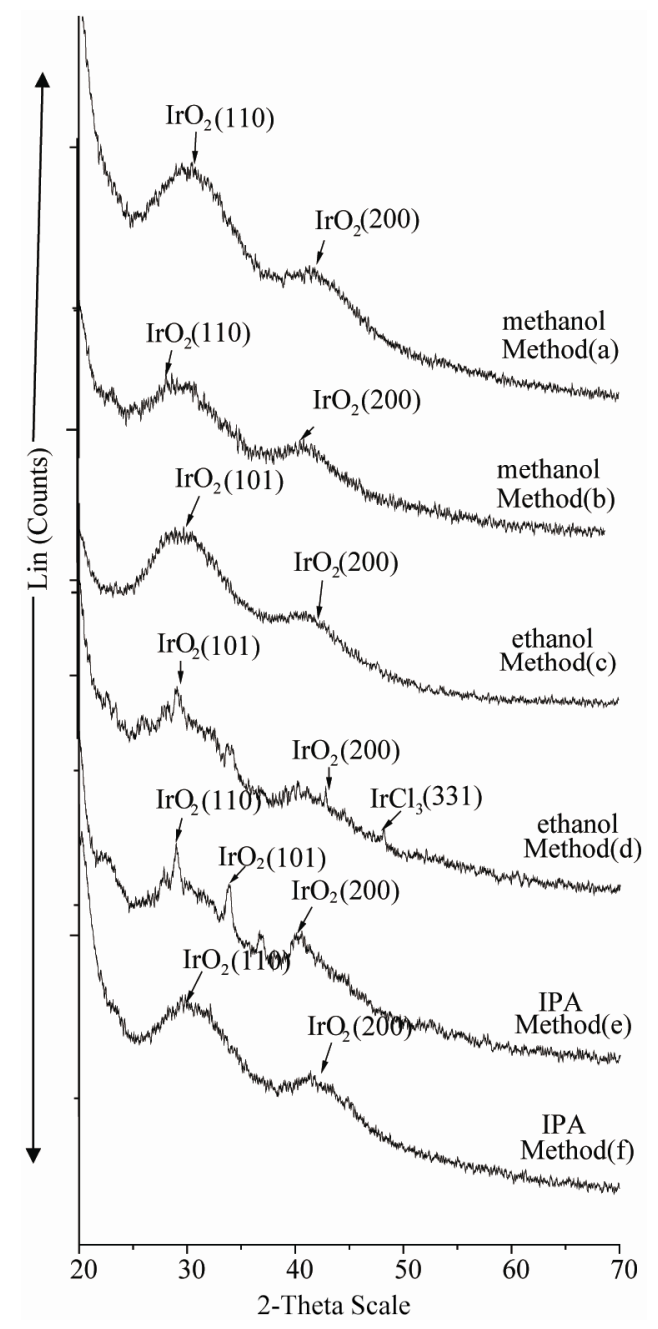

Figure 3. XRD spectra of Ir-nano with methanol, ethanol and IPA using PVA as stabilizer.

creases the size distribution i.e. with $35 \mathrm{ml}$ of methanol particle diameter is 3.16 to $5.67 \mathrm{~nm}$ which becomes less disperse from 4.12 to 4.23 with $25 \mathrm{ml}$ of methanol (a \& b) respectively. It may be due to the fact that the size of colloidal metal particle depends on the speed of oxidation of the metal precursor. Data also reveal that particle size is large when ethanol and propanol are the oxidant.

PVA stabilized Ir-nano: The results in Table 2 show that Ir-nano clusters synthesized using PVA stabilizer are smallest as compared to PVP and POLE. The particles are small with size distribution between 2.65 to $11.95 \mathrm{~nm}$. The data also reveal that particles synthesized by method a \& e are small with size distribution of 2.74 to 3.36 and 3.15 to $4.03 \mathrm{~nm}$ respectively. It also demonstrates the amorphous nature of Ir-nano synthesized by method a, b \& c. With methanol and ethanol particle size increases by decreasing PVA concentration, while in case of 2propanol particle size decreases with the decreases of PVA conc.

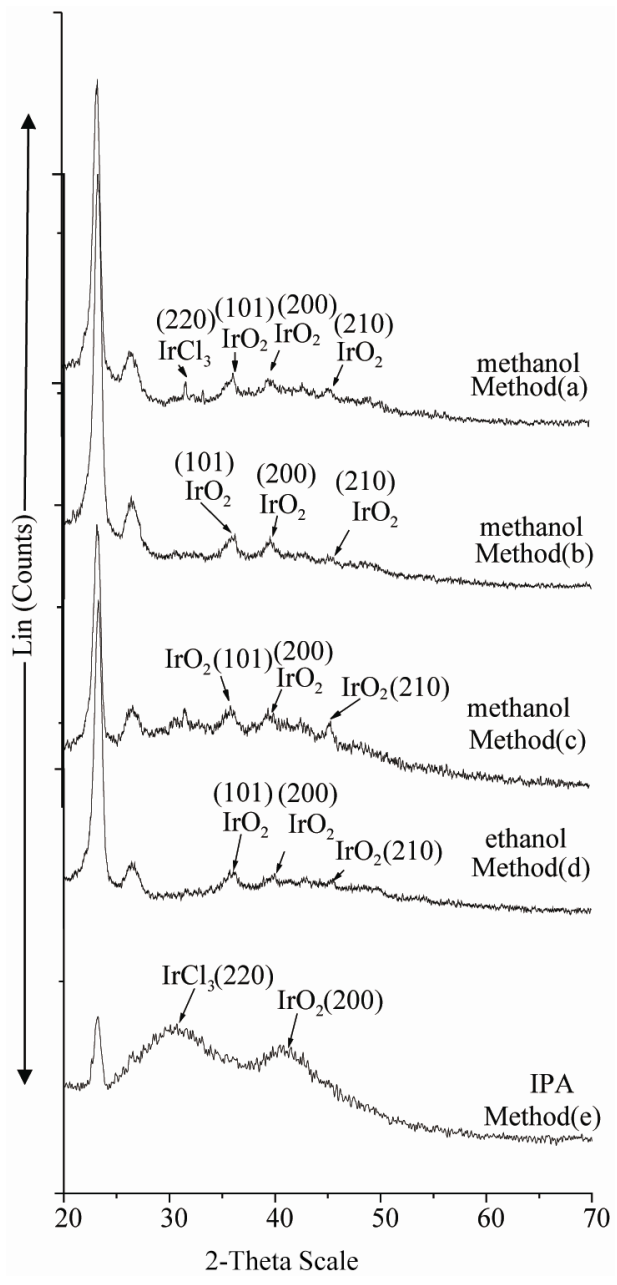

Figure 4. XRD spectra of Ir-nano with methanol, ethanol, and IPA using POLE as stabilizer.

POLE stabilized Ir-nano: From Table 3, it can be seen that size of Ir-nano synthesized using POLE stabilizer are large ranging from 4.03 to $42.25 \mathrm{~nm}$. It is smallest (4.03 to $4.11 \mathrm{~nm}$ ) (method-e) when 2-propanol is used as oxidant, while with methanol and ethanol the size of particle is large ranging from 20.41 to $42.25 \mathrm{~nm}$. It can also be seen that with the increase of oxidant concentration (method-b) the range of particle size distribution decreases from 27.22 to $42.25 \mathrm{~nm}$ to 20.41 to 42.25 $\mathrm{nm}$. With the decrease in stabilizer POLE concentration (method-c) the particle size decreases to 16.38 from $28.45 \mathrm{~nm}$. It can be revealed that Ir-nano using 2-propanol are more amorphous than with methanol and ethanol.

Role of stabilizer: The main effect of stabilizers on particle size may be due to the steric effect and chemical bonding [16]. The stabilization of colloidal metal particles with polymers [17-19] in water is often discussed by the adsorption of the polymer on the colloidal particles. These large adsorbates provide a steric barrier which 


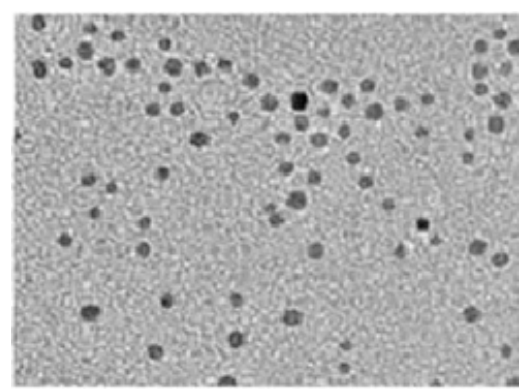

(a)
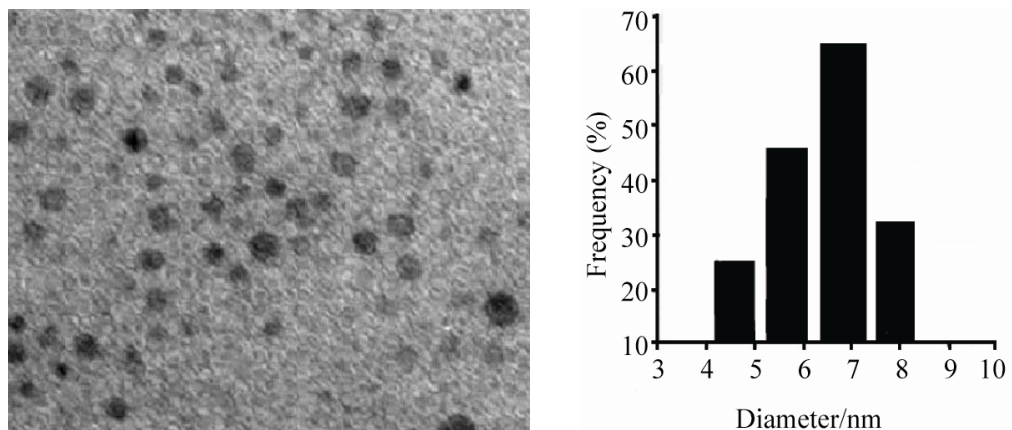

(b)
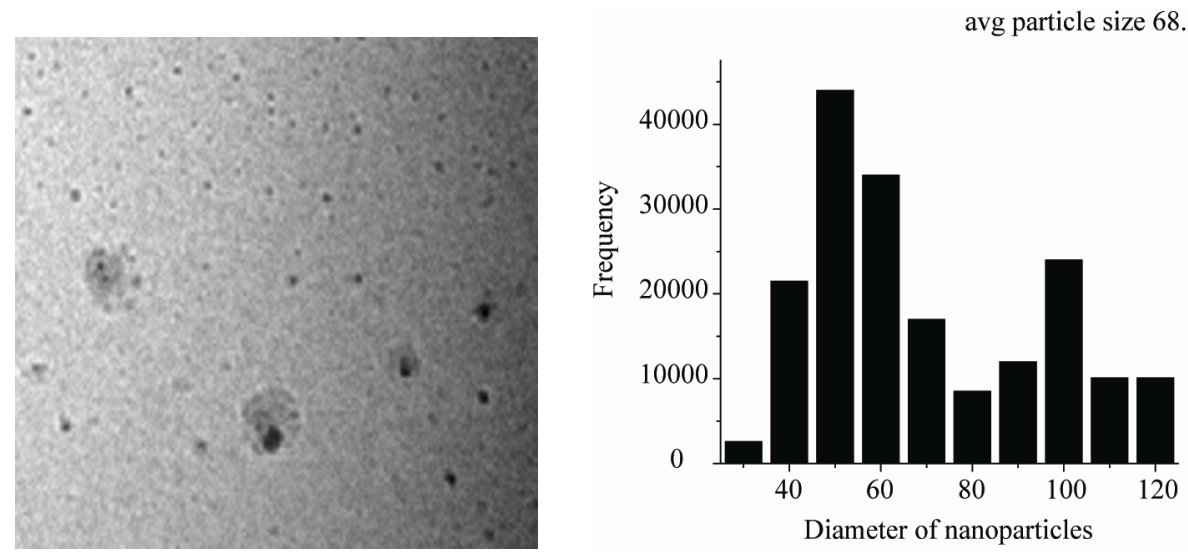

(c)

Figure 5. (a) TEM pictures of the iridium nanoparticles prepared by reduction method (b) using PVP as protective agent; (b) TEM pictures of the iridium nanoparticles prepared by reduction method (a) using PVA as protective agent; (c) TEM pictures of the iridium nanoparticles prepared by reduction method (a) using POLE as protective agent.

prevents close contact of metal nanoclusters to each other as demonstrated in (Scheme 1) [20].

The interaction between the surface of the metal particles and the polymers is considered to be hydrophobic. However coordination of the polymer to metal particles has been proposed by the shift of the $>\mathrm{C}=\mathrm{O}$ stretching in the IR spectra of the PVP and PVA surrounding nanoparticles. It is reported that carbonyl group of PVP partly co-ordinate to the surface Pt and Pd atoms of Pt and Pd nanoparticles respectively [21-23]. PVP/PVA may play the same role for $\mathrm{Au}$ and other noble metal nanoparticles (Ir-nano).The large particle size and less stability of

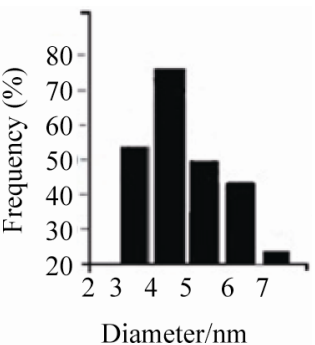

Diameter/nm 


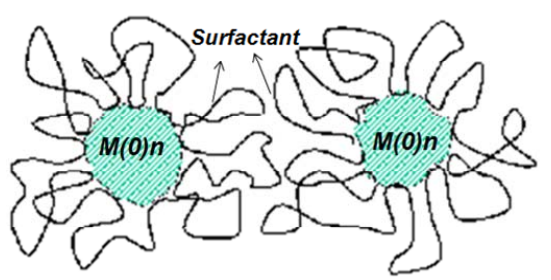

Scheme 1. The schematic representation of the steric stabilization of transition metalnanoclusters.

clear from the data that increase in $\mathrm{NaOH}$ concentration does not show any remarkable effect on particle size but the decrease in oxidant concentration increases the size distribution.

\section{ACKNOWLEDGEMENTS}

The authors are gratefully thankful to the support of UGC for providing financial assistance.

\section{REFERENCES}

[1] Roucoux, A., Schulz, J. and Partin, H. (2002) Reduced transition metal colloids: A novel family of reusable catalyst. American Chemical Society, 102, 3757-3778.

[2] Kishore, P.S., Viswanathan, B. and Varadarajan, T.K. (2008) Synthesis and characterization of metal nanoparticle embedded conducting polymer-polyoxometalate composites. Nanoscale Research Letters, 3, 14-20. doi:10.1007/s11671-007-9107-z

[3] Miyazaki, A., Balint, I. and Nakano, Y. (2003) Morphology control of platinum nanoparticles and their catalytic properties. Journal of Nanoparticles Research, 5, 69-80. doi:10.1023/A:1024451600613

[4] Gledison, S.F., Giovanna, M., Sergio, R.T., Gerhard, H.F., Jonder, M., Maria, C.M. and Jairton, D. (2006) Synthesis and characterization of catalytic iridium nanoparticles in imidazolium ionic liquids. Journal of Colloid and Interface Science, 301, 193-204. doi:10.1016/j.jcis.2006.04.073

[5] Zhao, Y.-X., Hernandez-Pagan, E.A., Vargas-Barbosa, N.M., Dysart, J.L. and Mallouk, T.E. (2011) A high yield synthesis of ligand-free iridium oxide nanoparticles with high electrocatalytic activity. The Journal of Physical Chemistry Letters, 2, 402-406. doi:10.1021/jz200051c

[6] Cheng, J.-B., Zhang, H.-M., Ma, H.-P., Zhong, H.-X. and Zou, Y. (2009) Preparation of $\mathrm{Ir}_{0.4} \mathrm{Ru}_{0.6} \mathrm{MoxOy}$ for oxygen evolution by modified Adams' fusion method. International Journal of Hydrogen Energy, 34, 6609-6613. doi:10.1016/j.ijhydene.2009.06.061

[7] Yu, W., Liu, M., Liu, H. and Zheng, J. (1999) Prepration of polymer-stabilized nobel metal colloids. Journal of Colloid and Interface Science, 210, 218-221. doi:10.1006/jicis.1998.5938

[8] Bonet, F., Delmas, V., Grugeon, S., Herrera-Urbina, R.,
Silvert, P-Y. and Tekaia-Elhsissen, K. (1999) Synthesis of monodisperse $\mathrm{Au}, \mathrm{Pt}, \mathrm{Pd}, \mathrm{Ru}$ and Ir nanoparticle in ethylene glycol. Nanostructured Materials, 11, 12771284. doi:10.1016/S0965-9773(99)00419-5

[9] Tu, W. and Liu, H. (2000) Rapid synthesis of nanoscale colloidal metal clusters by microwave irradiation. Journal of Materials Chemistry, 10, 2207-2211. doi:10.1039/b002232m

[10] Chen, C. W., Tano, D. and Akashi, M. (2000) Colloidal platinum nanoparticles stabilized by vinyl polymers with Amide side chains; Disperson stability and catalytic activity in aqueous electrolytic solution. Journal of Colloid and Interface Science, 225, 349-358. doi:10.1006/jcis.2000.6731

[11] Solís, D. Vigueras-Santiago, E., Hernández-López, S., Gómez-Cortés, A., Aguilar-Franco, M. and CamachoLópez, M.A. (2008) Textural, structural and electrical properties of $\mathrm{TiO}_{2}$ nanoparticles using Brij-35 and P-123 as surfactants. Science and Technology of Advanced Materials, 9, 025003.

[12] Goel, A. and Sharma, S. (2009) Synthesis and characterization of nanocrystalline iridium oxide. International Transactions in Applied Science, 12, 243-251.

[13] Kundu, S. and Liang, H. (2011) Shape-selective formation and characterization of catalytically active iridium nanoparticle. Journal of Colloid and Interface Science, 354, 597-606. doi:10.1016/j.jcis.2010.11.032

[14] Baglio, V., Blasi, A.D., Denaro, T., Antonucci, V., Aricò1, A.S., Ornelas, R., Matteucci, F., Alonso, G., Morales, L., Orozco, G. and Arriaga, L.G. (2008) Synthesis, characterization and evaluation of $\mathrm{IrO}_{2}-\mathrm{RuO}_{2}$ electrocatalytic powdersfor oxygen evolution reaction. Journal of New Materials for Electrochemical Systems, 11, 105-108.

[15] Hirai, H., Chawanya, H. and Toshima, N. (1985) Colloidal palladium protected with poly(N-vinyl-2-pyrrolidone) for selective hydrogenation of cyclopentadiene. Reactive Polymers, 3, 127-141.

[16] Tu, W.-X. (2008) Study on the interaction between polyvinylpyrrolidone and platinum metal during the formation of the colloidal metal nanoparticles. Chinese Journal of Polymer Science, 26, 23-29.

[17] Marie-Christine D. and Didier A. (2004) Nanoparticles: Assembly, supramolecular chemistry, quantum-size-related properties, and applications toward biology, catalysis, and nanotechnology. Chemical Reviews, 104, 293346. doi:10.1021/cr030698+

[18] Ott, L.S., Hornstein, B.J. and Finke, R.G. (2006) A test of the transition-metal nanocluster formation and stabilization ability of the most common polymeric stabilizer, poly(vinylpyrrolidone), as well as four other polymeric protectants. Langmuir, 22, 9357-9367. doi:10.1021/la060934m

[19] Jia, C.-J. and Schüth, F. (2011) Colloidal metal nanoparticles as a component of designed catalyst. Physical Chemistry Chemical Physics, 13, 2457-2487. doi:10.1039/c0cp02680h

[20] Narayanan, R. and Mostafa, A.S.El. (2005) Catalysis with transition metal nanoparticles in colloidal solution: Nano- 
particle shape dependence and stability. The Journal of Physical Chemistry B, American Chemical Society, 109, 12663-12676.

[21] Toshima, N., Nakata, K. and Kitoh, H. (1997) Gaint platinum clusters with organic ligand: Prepration and catalysis. Inorganic Chimica Acta, 265, 149-153. doi:10.1016/S0020-1693(97)05690-9

[22] Teranishi, T. and Miyake, M. (1998) Size control of pal- ladium nanoparticles and their crystal structures. Chemistry of Materials, 10, 594-600. doi:10.1021/cm9705808

[23] Tan, Y.-W., Dai, X.-H., Y.-F. Li and D.-B. Zhu (2003) Preparation of gold, platinum, palladium and silver nanoparticles by the reduction of their salts with a weak reductant-potassium bitartrate. Journal of Materials Chemistry, 13, 1069-1075. 